\title{
C-reactive protein can upregulate VEGF expression to promote ADSC-induced angiogenesis by activating HIF-1a via CD64/PI3k/Akt and MAPK/ERK signaling pathways
}

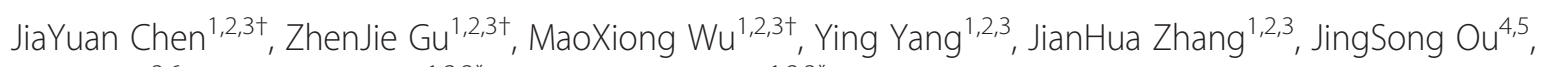
ZhiYi Zuo ${ }^{3,6}$, JingFeng Wang ${ }^{1,2,3^{*}}$ and YangXin Chen ${ }^{1,2,3^{*}}$

\begin{abstract}
Background: Proliferation of the vasa vasorum has been implicated in the pathogenesis of atherosclerosis, and the vasa vasorum is closely associated with resident stem cells within the vasculature. C-reactive protein (CRP) is positively correlated with cardiovascular disease risk, and our previous study demonstrated that it induces inflammatory reactions of perivascular adipose tissue by targeting adipocytes.

Methods: Here we investigated whether CRP affected the proliferation and proangiogenic paracrine activity of adipose-derived stem cells (ADSCs), which may contribute to vasa vasorum angiogenesis.

Results: We found that CRP did not affect ADSC apoptosis, cell cycle, or proliferation but did increase their migration by activating the PI3K/Akt pathway. Our results demonstrated that CRP can upregulate vascular endothelial growth factor-A (VEGF-A) expression by activating hypoxia inducible factor-1a (HIF-1a) in ADSCs, which significantly increased tube formation on Matrigel and functional vessels in the Matrigel plug angiogenesis assay. The inhibition of CRP-activated phosphorylation of ERK and Akt can suppress CRPstimulated HIF-1a activation and VEGF-A expression. CRP can also stimulate proteolytic activity of matrix metalloproteinase-2 in ADSCs. Furthermore, CRP binds activating CD64 on ADSCs, rather than CD16/32.
\end{abstract}

Conclusion: Our findings implicate that CRP might play a role in vasa vasorum growth by activating the proangiogenic activity of ADSCS.

Keywords: C-reactive protein, Angiogenesis, Adipose-deprived stem cell, Vascular endothelial growth factor, Hypoxia-inducible factor-1a

\section{Background}

C-reactive protein (CRP), an acute-phase protein and a member of the pentraxin family, members of which are characterized by a cyclic pentameric structure, exhibits $\mathrm{Ca}^{2+}$-dependent binding to ligands and binds to the membrane of injured cells as well as the membrane and

\footnotetext{
*Correspondence: dr_wjf@hotmail.com; tjcyx1995@163.com ${ }^{\dagger}$ Equal contributors

'Department of Cardiology, Sun Yat-sen Memorial Hospital, Sun Yat-sen University, Guangzhou 510120, People's Republic of China

Full list of author information is available at the end of the article
}

nuclear components of necrotic and apoptotic cells [1]. Baseline circulating concentrations of CRP are significantly associated with cardiovascular disease risk in the general population [2]. Recent clinical trials and basic research demonstrated that CRP could be a proatherogenic factor for atherosclerosis [3], whereas in-vitro experiments reported that CRP preparations had been contaminated by bacterial products or other contaminated preparations $[4,5]$, and a recent study showed that no proinflammatory cytokines or acute phase proteins were detected after purified CRP from pooled normal 
human donor plasma was infused into seven healthy adult human volunteers [6]. All evidence indicates that the functions of CRP still remain controversial as a biomarker or mediator.

Research into the pathogenesis of atherosclerosis has focused historically on the intima and media. However, recent studies demonstrated that adventitial vasa vasorum angiogenesis and periadventitial adipose tissue inflammation play an important role in the development of coronary atherosclerosis, known as the "outside-in" phenomenon $[7,8]$. Manka et al. [9] reported that the transplantation of perivascular adipose tissue (PVAT) from donor mice to the carotid arteries can promote vasa vasorum neovascularization in the adventitia, indicating that PVAT inflammation played a role in adventitia vasa vasorum angiogenesis. A certain amount of mesenchymal stem cells within adipose tissue, including PVAT [10], were closely associated with new vessel angiogenesis [11]. Stem cells are thought to be quiescent or to cycle slowly under normal circumstances, and the biological function of stem cells is activated by microenvironmental reactions such as inflammation, hypoxia, and oxidative stress. Whether PVAT inflammation could promote mesenchymal stem cell-induced vasa vasorum angiogenesis is not clearly understood.

PVAT inflammation is often accompanied by increased circulating CRPs. Because we know that the imbalance of adiponectin and leptin is the main cause of adipose tissue inflammation, increased leptin is able to further promote CRP production from hepatocytes and endothelial cells [12]. It is therefore interesting to investigate the role of CRP in PVAT inflammation. Our previous study showed that CRP could activate inflammatory reactions within PVAT by stimulating cultured adipocytes to release tumor necrosis factor alpha, interleukin-6, and monocyte chemoattractant protein-1 (MCP-1) and enhancing macrophage infiltration [13], indicating that CRP might act as a mediator in PVAT inflammation.

On the other hand, CRP could be a potent activator of angiogenesis. Recent studies showed that the inhibition of endothelial cell angiogenesis and increased apoptosis by CRP may be attributed to the presence of sodium azide in CRP preparations. Slevin et al. [14] reported that CRP is associated with the formation of immature microvessels in vivo, which is significantly expressed by stroke neovessels. In vitro, CRP can increase vascular endothelial growth factor (VEGF)-A expression in bovine aortic endothelial cells, human coronary artery endothelial cells, and monocytes, which was due to CRP itself but not the effects of sodium azide and lipopolysaccharide (LPS) contamination [15-17]. However, whether CRP can also promote the proliferation and proangiogenic paracrine activity of adipose-derived stem cells (ADSCs) as an angiogenic factor, which contribute to PVAT inflammation- related vasa vasorum angiogenesis, is still poorly defined. We hypothesized that human CRP promotes ADSCinduced angiogenesis in the setting of atherosclerosis. To test this hypothesis, we investigated the role of CRP on the proliferation, migration, and paracrine proangiogenic activity of ADSCs and identified the signaling pathways and the molecular mechanisms in vitro.

\section{Methods}

\section{Mouse ADSC isolation and cell culture}

Primary mouse ADSCs from mouse adipose tissue were isolated and cultured as described previously with minor modifications [18]. The fatty tissue around the inguinal region of male C57/BL6 mice, 3-4 weeks old, was separated. After the removal of visible blood vessels, lymph nodes, and fascia, the tissue was finely minced with scissors and digested with collagenase type I $(1.25 \% \mathrm{w} / \mathrm{v})$ for $60 \mathrm{~min}$ at $37^{\circ} \mathrm{C}$ with gentle shaking. After collagenase neutralization, the floating adipocytes were separated by centrifugation at $1200 \mathrm{rpm}$ for $5 \mathrm{~min}$. The resulting pellet was resuspended and the cells were plated in tissue culture flasks in Dulbecco's modified Eagle's medium with low glucose (DMEM; Gibco, Thermo Fisher Scientific, Inc., Waltham, MA, USA) supplemented with $10 \%$ fetal bovine serum (FBS; Gibco, Thermo Fisher Scientific, Inc.), $100 \mathrm{U} / \mathrm{ml}$ penicillin and $0.1 \mathrm{mg} / \mathrm{ml}$ streptomycin (both from Thermo Fisher Scientific, Inc., Waltham, MA, USA), VEGF $10 \mathrm{ng} / \mathrm{ml}$, basic fibroblast growth factor (FGF) $10 \mathrm{ng} / \mathrm{ml}$, and alpha-FGF $10 \mathrm{ng} / \mathrm{ml}$ (Sigma-Aldrich, St. Louis, MO, USA) at $37{ }^{\circ} \mathrm{C}$ in a $5 \% \mathrm{CO}_{2}$ humidified atmosphere.

\section{Flow cytometry analysis}

Cell apoptosis was detected by an Annexin V-FITC apoptosis detection kit according to the manufacturer's instructions. The cells were incubated with or without the addition of various concentrations of recombinant human CRP (free of sodium azide; Sino Biological Inc., Beijing, China) for different times and then harvested and rinsed in cold phosphate-buffered saline (PBS). The fraction of apoptotic cells was determined by cell staining in Annexin- $\mathrm{V}$ binding buffer with FITC-conjugated Annexin- $\mathrm{V}$ and propidium iodide (PI; Sigma-Aldrich). After $15 \mathrm{~min}$ of incubation in the dark at room temperature, the samples were analyzed by flow cytometry (LSRII FACS; BD Bioscience, Franklin Lakes, NJ, USA). Apoptotic cells were identified as Annexin-V-positive cells.

For the cell cycle analysis, the cells were trypsinized and fixed in $75 \%$ ethanol for $60 \mathrm{~min}$ on ice and stained with PI and Hoechst $33342(5 \mu \mathrm{g} / \mathrm{ml}$; Thermo Fisher Scientific, Inc.) in PBS for $30 \mathrm{~min}$. Equal numbers of cells were assessed for ADSCs by flow cytometry analysis. 


\section{Cell proliferation assay}

ADSCs were seeded in 96-well plates at a density of $4 \times 10^{3}$ cells/well. After 24, 48, and 72 hours, the medium was removed and cells were counted using a Cell Counting Kit-8 (CCK-8; Dojindo, Rockville, MD, USA). Cells were treated with $10 \%$ CCK- 8 solution for 4 hours at $37{ }^{\circ} \mathrm{C}$ in a humidified $5 \% \mathrm{CO}_{2}$ incubator and the absorbance was measured at $450 \mathrm{~nm}$ by a microplate reader.

\section{Cell migration assay}

ADSCs were seeded on the upper site of $8.0 \mu \mathrm{m}$ transwell membrane plates (Corning, Inc., NY, USA) at a density of $5 \times 10^{4}$ cells per well after serum starvation for 12 hours. CRP $(25 \mu \mathrm{g} / \mathrm{ml})$ or plus inhibitors (PD098059, $10 \mu \mathrm{M}$; LY294002, $5 \mu \mathrm{M})$ in DMEM were introduced on the lower site of transwell membrane plates for 12-24 hours. Migrated cells remaining in the transwell membrane were fixed and then stained using $10 \%$ crystal-violet (SigmaAldrich), and cells in the membrane were counted by light microscopy.

\section{Inhibitor and block antibody treatment}

After reaching $80 \%$ confluence, ADSCs were seeded in six-well plates $\left(5 \times 10^{5}\right.$ cells/well). The cells were treated with the following reagents for 24 hours: (a) ADSC basal medium as a control; (b) stimulant CRP alone; (c) stimulant plus inhibitors or block antibodies, including ERK inhibitor (PD098059, $10 \mu \mathrm{M}$ ), PI3K inhibitor (LY29 4002, $5 \mu \mathrm{M}$ ), and nuclear factor-kappa beta (NF-kB) inhibitor (BAY-11-7082, $5 \mu \mathrm{M}$ ) (all from Cell Signaling Technology, Danvers, MA, USA), or anti-CD16 $(2 \mu \mathrm{g} / \mathrm{ml}$; R\&D Systems, Inc., Madison, WI, USA), anti-CD16/32 (1 $\mu \mathrm{g} / \mathrm{ml}$; Abcam Inc., Cambridge, UK), and anti-CD64 (1:100, $3 \mu \mathrm{g} / \mathrm{ml}$; R\&D Systems Inc.); or (d) inhibitors and block antibodies alone. Doses of the inhibitors or block antibodies were determined according to previous laboratory characterization and published data. Supernatants and cell extractions were collected 24 hours after treatment.

\section{In-vitro tube formation assay}

Tube formation on Matrigel was performed as described previously [19]. A total of $50 \mu \mathrm{l}$ of chilled Matrigel (BD Bioscience) was added to a 96-well plate and incubated at $37{ }^{\circ} \mathrm{C}$ for $30 \mathrm{~min}$. Human umbilical vein endothelial cells (HUVECs; $1 \times 10^{4}$ cells) were suspended in $100 \mu \mathrm{l}$ of EBM-2 or endothelial growth medium (EGM; LONZA Inc., Basel, Switzerland), and conditioning medium (CM) of ADSCs, CRP-treated CM of ADSCs or plus VEGF-neutralizing antibody $(0.15 \mu \mathrm{g} / \mathrm{ml}$; R\&D Systems Inc.), or EBM-2 plus CRP was added to the solidified Matrigel. The $\mathrm{CM}$ was harvested after incubation of the ADSCs in EBM2 for 24 hours. After incubation on Matrigel at $37{ }^{\circ} \mathrm{C}$ in a $5 \% \mathrm{CO}_{2}$ chamber, morphological changes were observed under a microscope (Leica, Germany). The five representative fields were photographed. Images were analyzed using Image J software (NIH, Bethesda, MD, USA) to determine the tube lengths.

\section{In-vivo Matrigel plug assay}

The animal experiments were conducted according to the guidelines and ethical standards of the Animal Care and Use Ethics Committees of Sun Yat-Sen University (IACUC-DB-16-070). ADSC (100 $\mu \mathrm{l}, 1 \times 10^{6}$ cells) or CRP-treated ADSC (24-hour pretreatment with $25 \mu \mathrm{g} / \mathrm{ml}$ CRP without FBS, $1 \times 10^{6}$ cells) suspensions were mixed with $400 \mu \mathrm{l}$ of ice-cold growth factor reduced phenol redfree Matrigel (BD Bioscience), and Matrigel containing PBS was used as a negative control. The Matrigel mixture was injected subcutaneously into the dorsal area of male nu/nu mice, 4-5 weeks old. Each experimental condition was performed with three mice. At day 7, the Matrigel implants were removed and then fixed with formalin, and the fixed Matrigel plug was embedded in paraffin to prepare sections for hematoxylin and eosin (H \& E).

\section{Enzyme-linked immunosorbent assay}

The assay was performed for the CM using a mouse angiogenesis array kit (R\&D Systems, Inc.) according to the manufacturer's instructions. VEGF-A production was examined by enzyme-linked immunosorbent assay (ELISA) using a commercially available kit (Raybiotech, Atlanta, GA, USA) according to the manufacturer's instructions.

\section{Western blot analysis}

To prepare the protein extracts, the cells were rinsed twice with ice-cold PBS and harvested. After centrifugation, the cells were resuspended and extracted in lysis buffer (Thermo Fisher Scientific, Inc.) for $30 \mathrm{~min}$ on ice. Protein concentrations were assayed using Pierce Coomassie Plus reagent according to the manufacturer's instructions, and $40 \mu \mathrm{g}$ of protein was loaded for separation by sodium dodecyl sulfate-polyacrylamide gel electrophoresis (SDSPAGE). The proteins were then transferred to polyvinylidene difluoride membranes (Immobilon-P; EMD Millipore Corporation, Billerica, MA, USA). The membranes were blocked in Tris-buffered saline containing $5 \%$ bovine serum antigen (BSA) and probed with HIF-1a, tissue inhibitor of metalloproteinase-2 (TIMP-2), VEGF-A, hepatocyte growth factor (HGF), matrix metalloproteinase (MMP)-2, and MMP-9 (all from R\&D Systems Inc.) corresponding antibodies. Reacted bands were detected by horseradish peroxidase-conjugated secondary antibodies and enhanced chemiluminescence substrates (PerkinElmer, Boston, MA, USA). 


\section{Quantitative real-time PCR}

Total RNA was extracted using Trizol reagent (Thermo Fisher Scientific, Inc.). The synthesis of cDNA was performed on DNaseI-treated total RNA templates $(0.5 \mu \mathrm{g})$ using an iscript ${ }^{\text {tw }}$ cDNA synthesis kit. Gene expression was assessed by quantitative real-time PCR (qRT-PCR) using SYBR Green intercalating dye (Thermo Fisher Scientific, Inc.) and mouse primers. The primer sequences are presented in Additional file 1: Table S1. The comparative threshold cycle method was used to calculate the amplification fold as specified by the manufacturer. The amplified PCR products were separated by gel electrophoresis in a $2 \%$ agarose gel visualized with ethidium bromide. Each sample was replicated at least three times.

\section{Immunofluorescence staining}

The ADSCs were fixed with $4 \%$ paraformaldehyde (PFA) for $10 \mathrm{~min}$, followed by blocking with $5 \%$ BSA in PBS for $60 \mathrm{~min}$ at room temperature. The cells were incubated with the following antibodies at room temperature for 1 hour: rabbit anti-CD16/32 (1:200; Abcam Inc.) and rabbit antiCD64 (1:200; Santa Cruz Biotechnology, Inc., Santa Cruz, CA, USA). Following a wash in PBS, the cells were incubated in goat anti-rabbit secondary antibodies conjugated with FITC (1:200; Thermo Fisher Scientific, Inc.) in PBS for 1 hour at room temperature. DAPI was used for the nuclear stain. The samples were then washed three times, and mounted in mounting medium (Vector Laboratories, Burlington, CA, USA). Images were obtained using an inverted fluorescence microscope.

\section{Immunoprecipitation}

The ADSCs were incubated with CRP $(25 \mu \mathrm{g} / \mathrm{ml})$ for 6 hours and then washed and lysed in $1 \mathrm{ml}$ of RIPA buffer. Cell lysates were precipitated with goat antibodies against CRP (2 $\mu \mathrm{g}$ per $100 \mathrm{~g}$ of total protein; Santa Cruz Biotechnology, Inc.) that had been preabsorbed by protein G-Sepharose (Biotool Inc., Houston, TX, USA). Immunoprecipitated proteins were washed in RIPA buffer, subjected to SDS-PAGE, and immunoblotted with specific antibodies against CRP (Santa Cruz Biotechnology, Inc.) or FcgRs (1:200; R\&D Systems, Inc.).

\section{Statistical analysis}

The in-vitro data are representative of independent experiments performed in triplicate. The statistical analysis was conducted using SPSS software (SPSS, Inc., Chicago, IL, USA). The statistical significance of the differences among groups was tested using one-way analysis of variance or Student's $t$ test. Error bars are indicative of standard deviation. $p<0.05$ or $p<0.01$ was considered significant.

\section{Results}

\section{Characterization of ADSCs}

In this study, we isolated ADSCs from the mouse adipose tissue; the isolated cells were plastic adherent and exhibited spindle-like morphology with a whirlpool-like, colony-forming unit (CFU) of ADSCs (Additional file 1: Figure S1B1, B2). The cells were positive for mesenchymal markers (CD29, CD44, CD90, and SCA-1), and were negative for endothelial (CD105 and CD31), pericyte (CD146), and hematopoietic (TER-119, CD45) markers (Additional file 1: Figure S1A). In addition, the cells were able to differentiate into mesenchymal lineage cells such as adipocytes and osteocytes (Additional file 1: Figure S1B3, B4). Thus, we confirmed that the cells derived from adipose tissue have typical MSC characteristics.

\section{CRP did not affect ADSC apoptosis or proliferation but increased migration via the PI3K/Akt signaling pathway}

Several previous studies demonstrated that CRP was associated with cell proliferation and apoptosis in endothelial cells, endothelial progenitor cells, renal tubular epithelial cells, and myeloma cells [20,21], but this is the first study to investigate the effect of CRP on ADSC proliferation and apoptosis. We found that CRP $(0-100 \mu \mathrm{g} / \mathrm{ml})$ treatment had no significant effects on ADSC proliferation at 24, 48, and 72 hours using a CCK-8 assay (Fig. 1a). CRP treatment slightly increased ADSC migration in a chamber migration assay, which was significantly suppressed by Akt inhibitor (LY294002) treatment (Fig. 1c), indicating that CRP increases ADSC migration via the PI3K/Akt signaling pathway. Our results also showed that CRP treatment did not induce ADSC apoptosis even in the presence of CRP at higher concentrations $(100 \mathrm{mg} / \mathrm{ml})$ by Annexin$\mathrm{V}$ binding analysis (data not shown), suggesting that CRP might play a different role in ADSC apoptosis induction.

Because cell cycle mechanisms control stem cell proliferation under normal conditions and stem cells generally remain in the quiescent $G_{0}$ phase in vivo, further investigations were performed to determine whether CRP affected cell cycle regulation by staining with PI and Hoechst 33342 . No significant difference was observed between any two groups at different CRP concentrations $(0-100 \mu \mathrm{g} / \mathrm{ml})$ in the distribution of each phase of the cell cycle (Fig. 1b), which is consistent with its function in ADSC proliferation.

\section{CRP treatment upregulates VEGF-A protein and production in ADSCS}

A recent study demonstrated that CRP preparations might have been contaminated by bacterial endotoxin byproducts and that LPS $(200 \mathrm{ng} / \mathrm{ml})$ could promote VEGF-A production in bone marrow-derived mesenchymal stem cells (BMSC) [22]. Accordingly, when we examined the changes of VEGF-A and HGF expression in ADSCs after CRP treatment at different concentrations $(0-50 \mu \mathrm{g} / \mathrm{ml})$ 

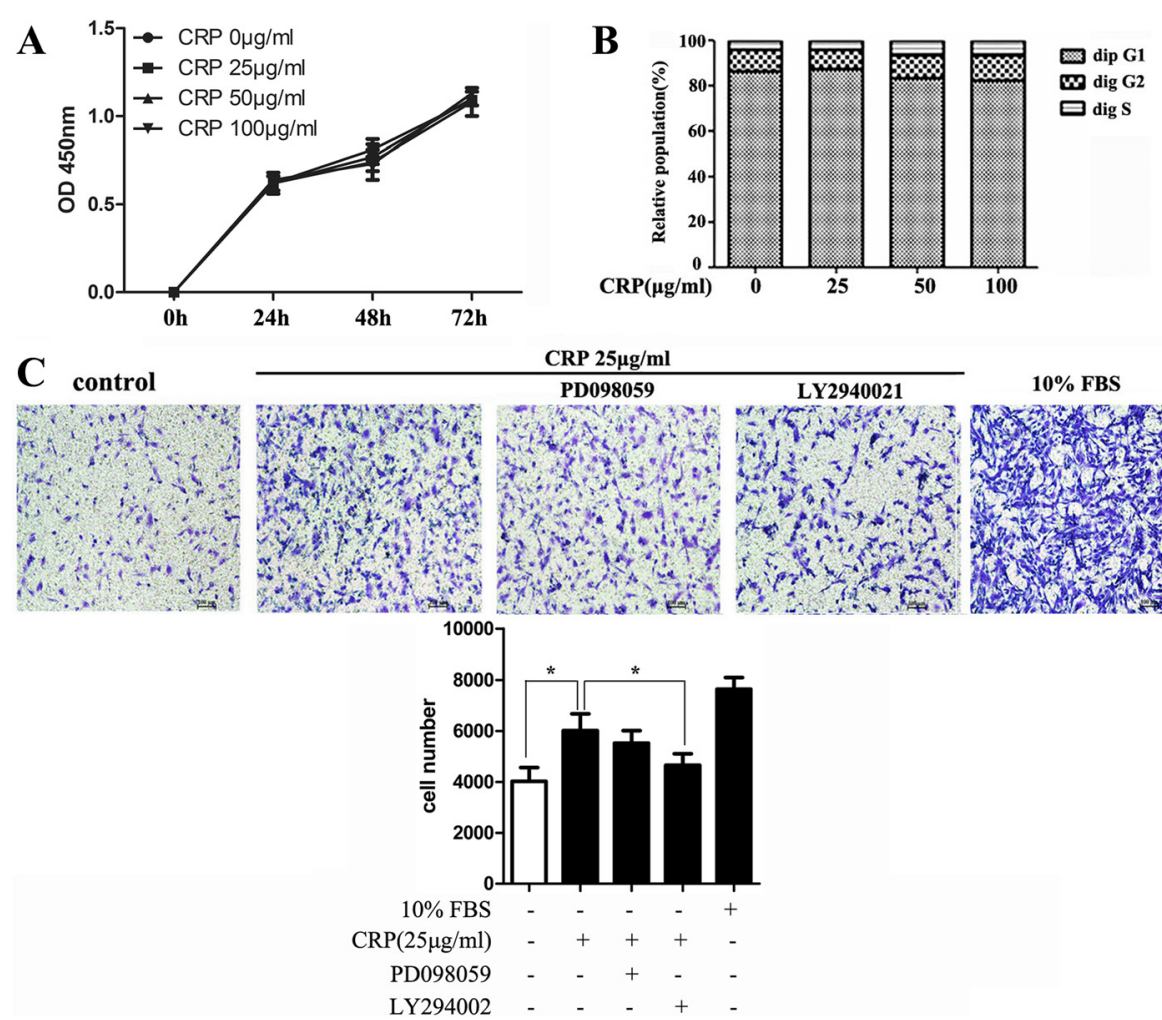

Fig. 1 CRP did not affect ADSC apoptosis or proliferation but slightly increased migration via the PI3K/Akt pathway. a Proliferation determined by a CCK-8 assay of ADSC cultures 24, 48, and 72 hours after addition of CRP. $\mathbf{b}$ Distribution of the cell cycle phase of ADSCs in 24-hour cultures with or without CRP treatment. c CRP increased the migration of ADSCS and inhibition of Akt (LY294002) significantly inhibited ADSC migration. Data represent mean $\pm \mathrm{SE}(n=3)$. Columns, mean; error bars, $\mathrm{SEM} ;{ }^{*} p<0.05$. Results are representative of three independent experiments. CRP C-reactive protein, $F B S$ fetal bovine serum, $O D$ optical density

respectively by western blotting and ELISA, we should exclude the effect of LPS potentially present in the CRP preparations. From the results we found that the VEGF-A protein levels were increased after CRP treatment in a dose-dependent manner (Fig. 2a), whereas the HGF protein levels were not. We found that CRP increased VEGF production in ADSCs in a dose-dependent and timedependent manner (Fig. 2b). VEGF-A protein expression and production was not abrogated by preincubation with polymyxin B $(5 \mu \mathrm{g} / \mathrm{ml})$, which is used to exclude the effect of LPS potentially present in CRP preparations (data not shown). Also CRP $25 \mu \mathrm{g} / \mathrm{ml}$ did not have a significant effect on adipogenic and osteogenic differentiation (Additional file 1: Figure S2).

\section{CRP-induced VEGF-A upregulation promotes angiogenesis in ADSCs}

We then examined the functions of CRP-induced VEGF$\mathrm{A}$ in angiogenesis, and the results demonstrated that HUVECs can form more tubes in ADSC growth medium than in basal medium. In addition, tube length was significantly increased in the CRP-treated ADSC supernatant compared with the normal ADSC supernatant but decreased compared with EGM. This induction effect of CRP can be significantly inhibited by VEGF-neutralizing antibody treatment (Fig. 2c). To further investigate whether CRP promotes ADSC-induced angiogenesis in vivo, the Matrigel plug assay was performed in nu/nu mice. Our results demonstrated that CRP-treated ADSC Matrigel implants showed more functional vessels containing erythrocytes than untreated ADSCs (Fig. 2d). Furthermore, we compared the expression levels of angiogenesis-related proteins in the condition medium (CM) of ADSCs with or without CRP treatment using a commercial antibody assay. Among 55 angiogenesis-related proteins, the expression levels of five were upregulated after CRP treatment-osteopontin, SDF-1, MCP-1, VEGF, and proliferin (Fig. 3)-which are reportedly associated with endothelial cell proliferation, migration, and/or tube formation in vitro.

\section{CRP promotes MMP-2 proteolytic activity in ADSCs}

MMP family members and their suppressor TIMP are the dominant factors in transformation of the extracellular matrix (ECM), which is closely related to angiogenesis, so we determined the levels of MMP and TIMP with CRP treatment in ADSCs. Firstly, quantitative determination of 

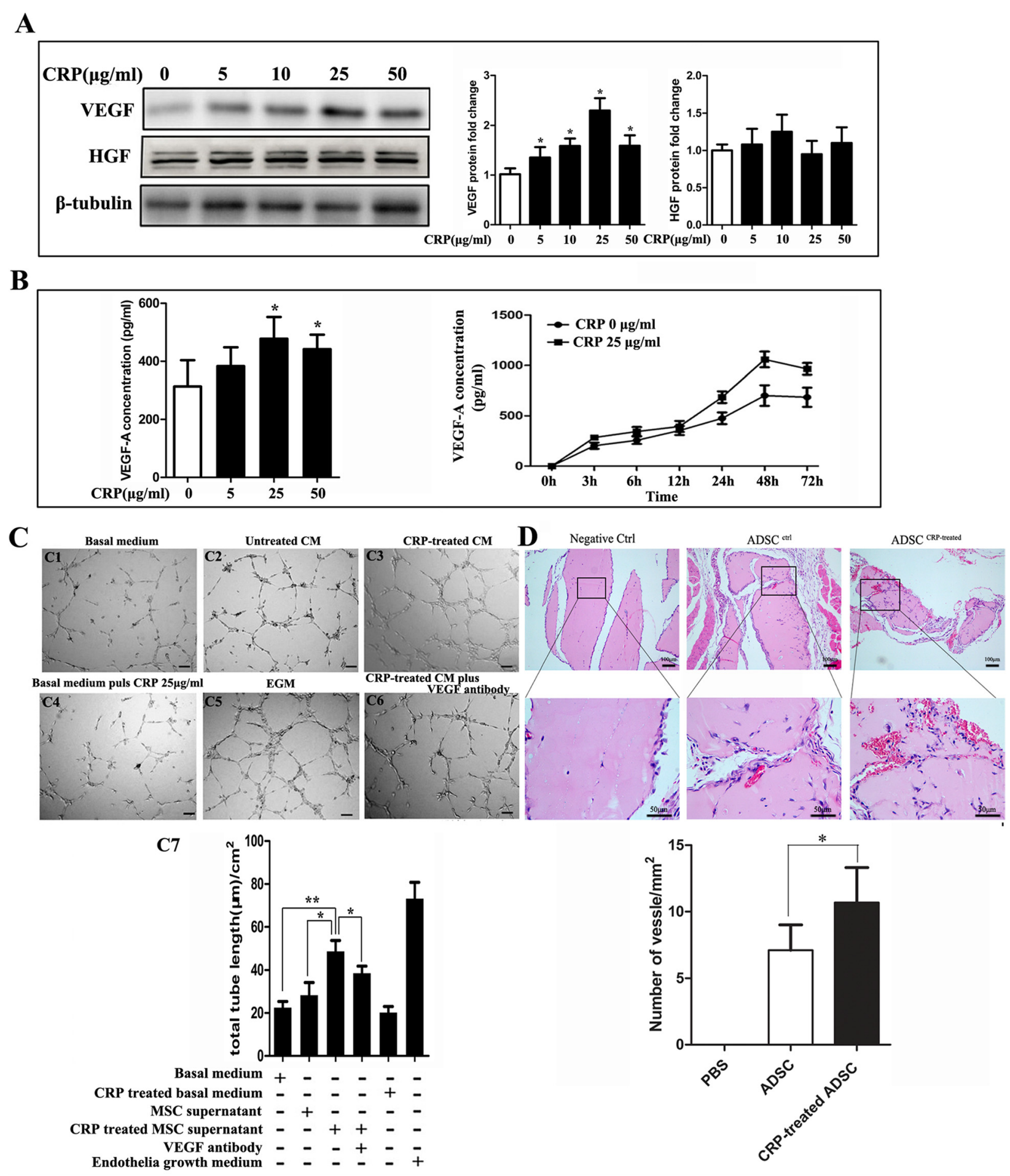

Fig. 2 (See legend on next page.) 
(See figure on previous page.)

Fig. 2 CRP treatment upregulates VEGF protein and production levels and promotes angiogenesis in ADSCs. a CRP increased VEGF but not HGF production as assessed by western blotting. Values were normalized to $\beta$-tubulin as a control, ${ }^{*} p<0.05$ versus control. $\mathbf{b}$ CRP increased VEGF production dose and time dependently as assessed by ELISA, peak at CRP $25 \mu \mathrm{g} / \mathrm{ml},{ }^{*} p<0.05$ versus control. c CRP-induced VEGF increased capillary tube formation in vitro. (C1) HUVECs formed tubes in basal medium; (C2) culturing of HUVECs in ADSC supernatant induced tube formation; (C3) CRP-treated ADSCS conditioned medium (CM) enhanced tube formation; (C4) CRP-treated basal medium slightly decreased the HUVEC tube formation; (C5) HUVECS formed tubes cultured in EGM as positive control; (C6) VEGF-neutralizing antibody in CRP-treated ADSC CM prevented HUVEC tube formation; (C7) representative histogram of tube length in different medium, ${ }^{*} p<0.05,{ }^{*} p<0.01$. d Mice were injected subcutaneously with Matrigel mixed with PBS, ADSCS, and CRP-pretreated ADSCs. At day 7, mice were sacrificed, explanted Matrigel plugs were excised and processed for H \& E staining (upper bars $100 \mu \mathrm{m}$, lower bars $50 \mu \mathrm{m}$ ) and light microscope, and microvessel density was quantified by counting vessel structures containing erythrocytes. Representative histogram of tube length in different medium, ${ }^{*} p<0.05$; data represent mean $\pm \operatorname{SEM}(n=3)$. Columns, mean; error bars, SEM. Results are representative of three independent experiments. CRP C-reactive protein, VEGF vascular endothelial growth factor, HGF hepatocyte growth factor, ADSC, adipose-derived stem cell, EGM endothelial growth medium, MSC mesenchymal stem cell

mRNA expression in ADSCs by RT-PCR revealed the transcription levels of MMPs and TIMPs compared with that of GAPDH. The expression of MMP-2 mRNA was higher than that of MMP-9, MT2-MMP and MT3-MMP mRNA, whereas MT1-MMP and TIMP-4 mRNA expression was undetectable (Fig. 4a). Moreover, our results showed that CRP treatment can increase MMP-9 mRNA and protein levels in a dose-dependent manner (Fig. 4b, c), but interestingly no MMP-9 activity was found in the supernatant of untreated or CRP-treated ADSCs, which meant MMP-9 activity might be totally suppressed by high-level secretion of TIMP-1 in ADSCs (Fig. 3). Because MMP-2 activity is regulated by MMP-2, TIMP-2, and MT-MMPs in stem cells [23], we next examined the effects of CRP treatment on MMP-2, TIMP-2, and MT-MMP levels. Both qRT-PCR assay and western blot analysis indicated that CRP significantly increased the mRNA and protein expressions of MMP-2 and TIMP-2, but had no effect on the expression of MT2-MMP and MT3-MMP (Fig. 4b, c). We also found that CRP induced MMP-2 proteolytic activity in the supernatant of ADSCs in a dose-dependent manner using gelatin zymography
(Fig. 4d). All evidence suggests that MMP-2 proteolytic activity might be further evidence for CRP-mediated angiogenesis in ADSCs.

CRP upregulates VEGF-A expression by activating HIF-1a via the PI3K/Akt and MAPK/ERK signaling pathways in ADSCs

It was observed that CRP treatment can remarkably induce ERK, Akt, and NF-kB phosphorylation (Fig. 5a). Then we found that the coincubation of cells with CRP and their pharmacological inhibitors of the MAPK pathway (PD98059) or the PI3K/AKT pathway (LY294002) could abrogate the effects of CRP-mediated phosphorylated kinases examined by WB or upregulation of VEGF-A production examined by ELISA in ADSCs, and cycloheximide, a protein expression inhibitor, reduced the increased VEGF-A production induced by CRP (Fig. 5b). However, no detectable difference was observed with or without the coincubation of NK-kB inhibitor (BAY-11-7082) (Fig. 5c).

Next, we further explored how CRP induced VEGF expression in transcriptional regulation. Regarding the amount of transcription factors such as HIF-1 $\alpha$, AP1, NF-

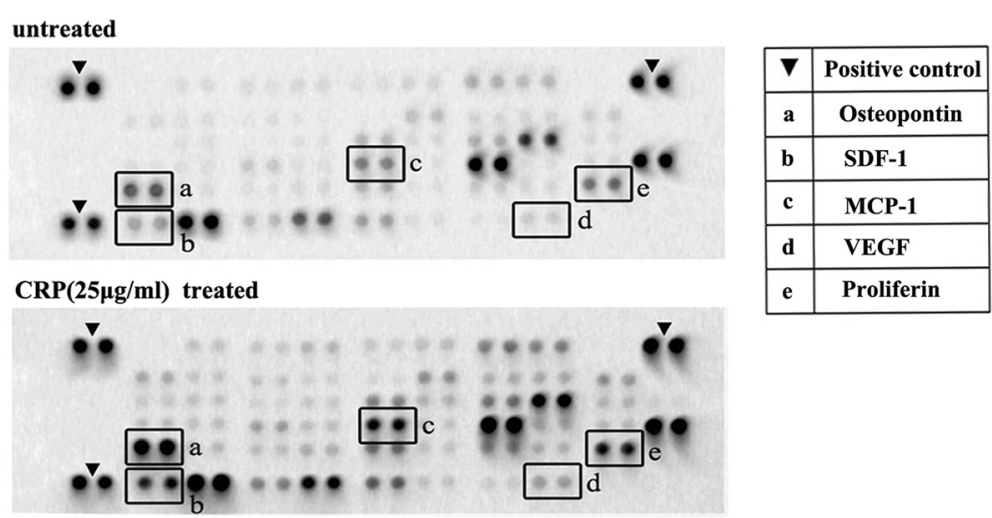

Fig. 3 CM with or without added CRP analyzed by antibody-based protein arrays. ADSCs were cultured with $10 \%$ FBS low-glucose DMEM until 80-90 \% confluence was reached and then incubated in DMEM for 24 hours. The CM was then collected for protein assays; increased proteins after CRP treatment are indicated with letters. CRP C-reactive protein, VEGF vascular endothelial growth factor 
A

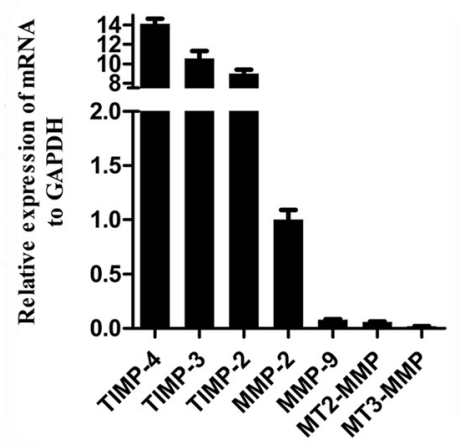

C

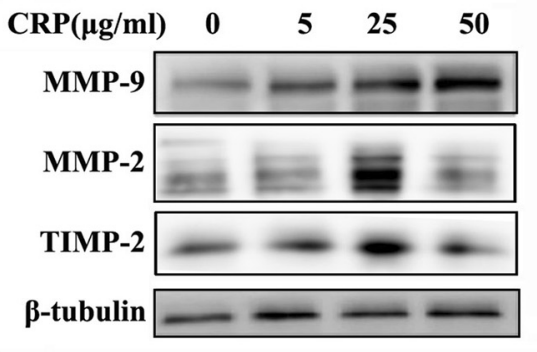

D
B

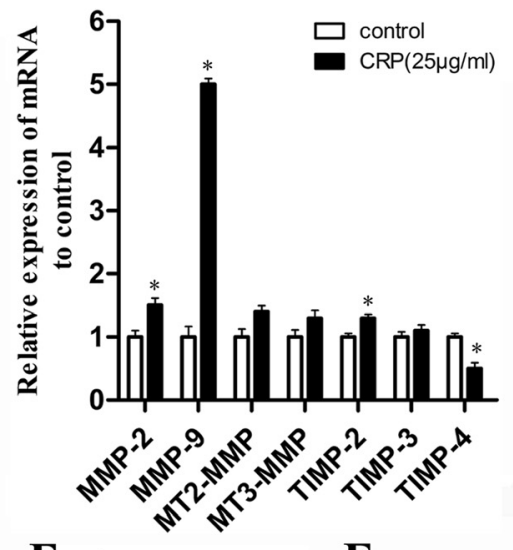

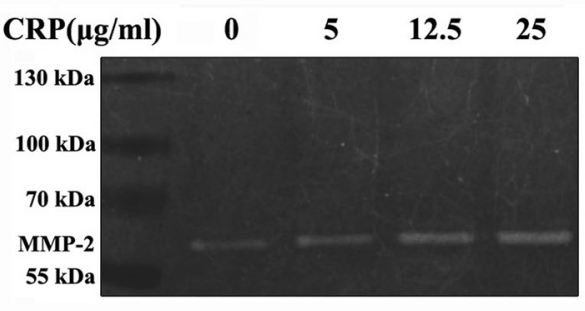
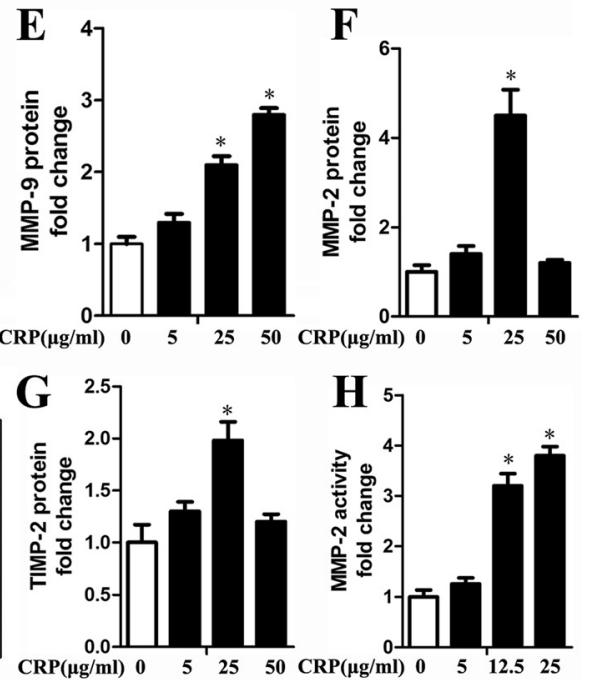

Fig. 4 CRP promotes MMP-2 proteolytic activity in ADSCs. a RT-PCR analysis of MMP-2, MMP-9, MT2-MMP, MT3-MMP, TIMP-2, TIMP-3, and TIMP-4 gene transcription in ADSCs. Results are mean values \pm SD of mRNA expression relative to GAPDH. $\mathbf{b}$ mRNA expression of MMPs and TIMPs quantified by RT-PCR after 24 hours of incubation with CRP $(25 \mu \mathrm{g} / \mathrm{ml})$ under serum-free conditions. Results given as the fold change in mRNA expression relative to untreated cells set as $1,{ }^{*} p<0.05$, versus control. $\mathbf{c}, \mathbf{e}, \mathbf{f}, \mathbf{g}$ CRP significantly increased the gene and protein expression of MMP-2, MMP-9 and TIMP-2. d CRP induced MMP-2 proteolytic activity in ADSCs, but MMP-9 proteolytic activity was undetected. ${ }^{*} p<0.05,{ }^{* *} p<0.01$ versus control; data represent mean \pm SE $(n=3)$. Columns, mean; error bars, SEM. Results are representative of three independent experiments. MMP matrix metalloproteinase, TIMP tissue inhibitor of metalloproteinase, CRP C-reactive protein

$\mathrm{kB}$, and SP1, HIF-1 $\alpha$ is most closely related to VEGF regulation in stem cells. Our results showed that CRP treatment can increase HIF-1 $\alpha$ protein expression levels in the nucleus (Fig. 6a). In contrast, further western blot analysis showed that CRP-induced regulation of HIF- $1 \alpha$ and VEGF-A protein expression can be suppressed by HIF-1 $\alpha$ inhibitor treatment (2-methoxyestradiol, $10 \mu \mathrm{M}$ ) (Fig. 6b), suggesting that CRP may promote HIF-1 $\alpha$ to enter the nucleus to induce VEGF expression in ADSCs. Furthermore, our results also showed that ERK and Akt inhibition can suppress CRP-stimulated HIF- $1 \alpha$ and VEGFA protein expression (Fig. $6 \mathrm{c}$ ), indicating that CRP-induced MAPK/ERK and PI3K/AKT pathway activations were related to HIF- $1 \alpha$ activation of VEGF expression in ADSCs.

\section{CD64 mediated CRP-induced VEGF expression regulation} in ADSCs

To understand how CRP acts on ADSCs, further studies were designed to reveal the way in which CRP binds to the ADSC membrane surface receptor. It is well known that CRP shares several functional properties with immunoglobulin $\mathrm{G}$ and binds to FcgRs, which are designated Fc gamma RI (also known as CD64), Fc gamma RII (CD32), and Fc gamma RIII (CD16). The findings of RT-PCR and immunofluorescence staining indicated that $\mathrm{CD} 16 / 32$ and CD64 were expressed in ADSCs (Fig. 7a, b). We found that CRP stimulation resulted in increased expression of CD64 mRNA in ADSCs, whereas the CD16 and CD32 mRNA levels showed no significant changes (Fig. 7c). We then 


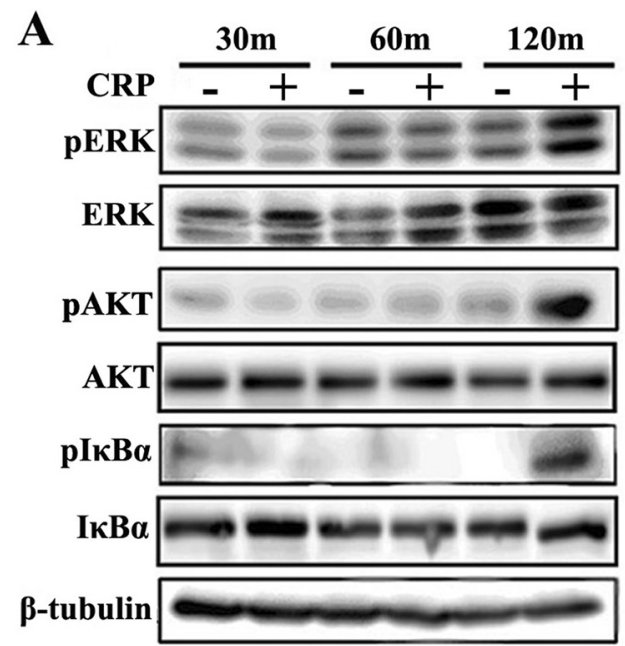

B
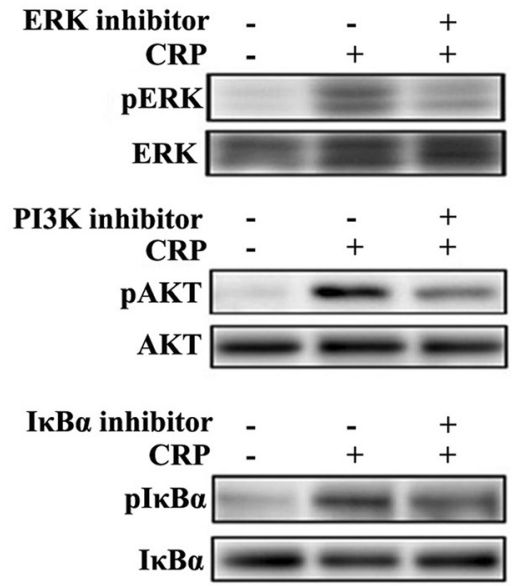

C

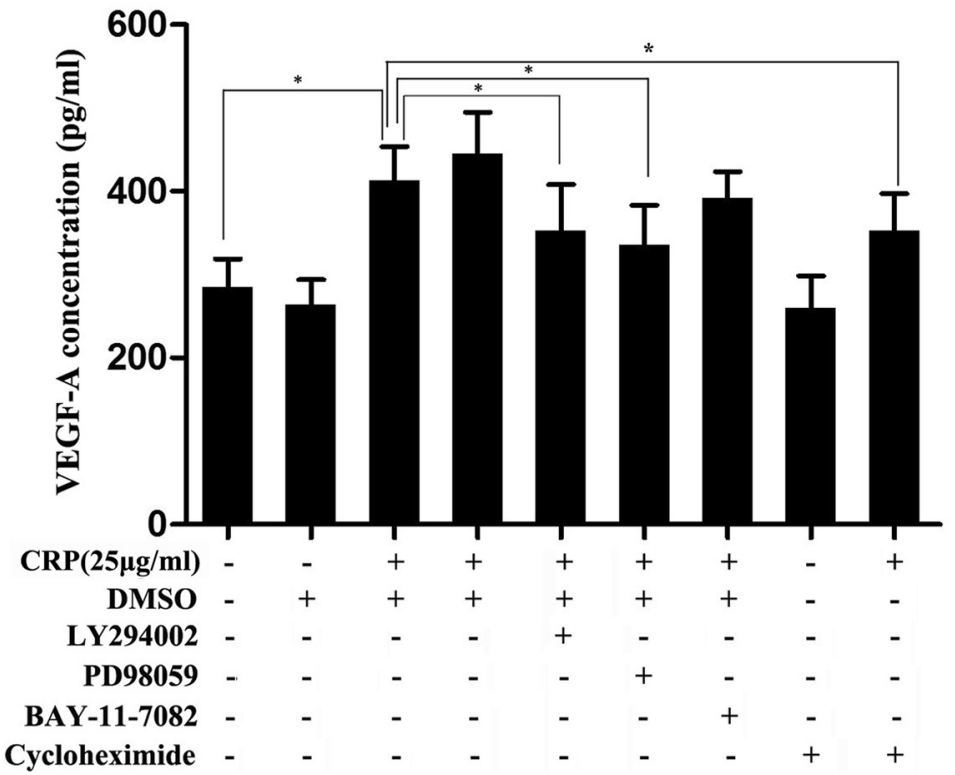

Fig. 5 CRP induces phosphorylation of ERK and Akt, and inhibiting both pathways abrogated the increasing of VEGF production. $\mathbf{a}$, $\mathbf{b}$ CRP induced phosphorylation of ERK, Akt, and NF-kB; the effect peaked at 120 min. Pharmacological inhibitors of MAPK (PD98059), PI3KJAKT (LY294002), and NF-KB

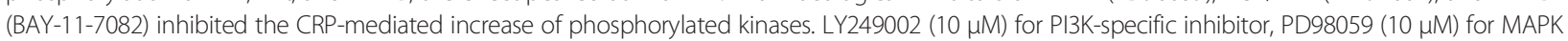

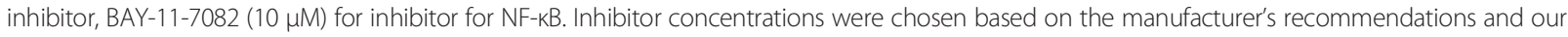
preliminary experimental findings. $\mathbf{c}$ Effects of kinase inhibitors on CRP-induced VEGF production examined by ELISA. Inhibition of the MAPK and PI3K/AKT signaling pathways but not NF-KB/lkBa and cycloheximide partly abrogated the increased CRP-induced VEGF production. Columns, mean; bars, SE. ${ }^{*} P<0.05$. The results are representative of three independent experiments. CRP C-reactive protein, VEGF vascular endothelial growth factor

examined the roles of CD16, CD32, and CD64 in CRPregulated VEGF production in ADSCs. Interestingly, specific blocking antibodies for both CD16 and CD16/32 had no significant effects on VEGF-A expression after CRP stimulation in ADSCs, whereas CD64-neutralizing antibody partially abrogated the effect of CRP treatment (Fig. 7d). Furthermore, immunoprecipitation with monoclonal antibodies (mAbs) against CRP was performed to examine whether and which FcgRs bind to CRP on ADSCs. We found that mAbs against CRP can precipitate
CD64 but not CD16/32 (Fig. 7e), suggesting that CRPregulated VEGF expression is CD64 dependent.

\section{Discussion}

Mesenchymal stem cell-induced angiogenesis was found to be regulated mainly by proangiogenic paracrine activity, such as high-level secretions of VEGF, HGF, FGF, and insulin-like growth factor (IGF) [24, 25], which can promote angiogenesis through stimulating endothelial cell maturity, migration, and proliferation. Among these 


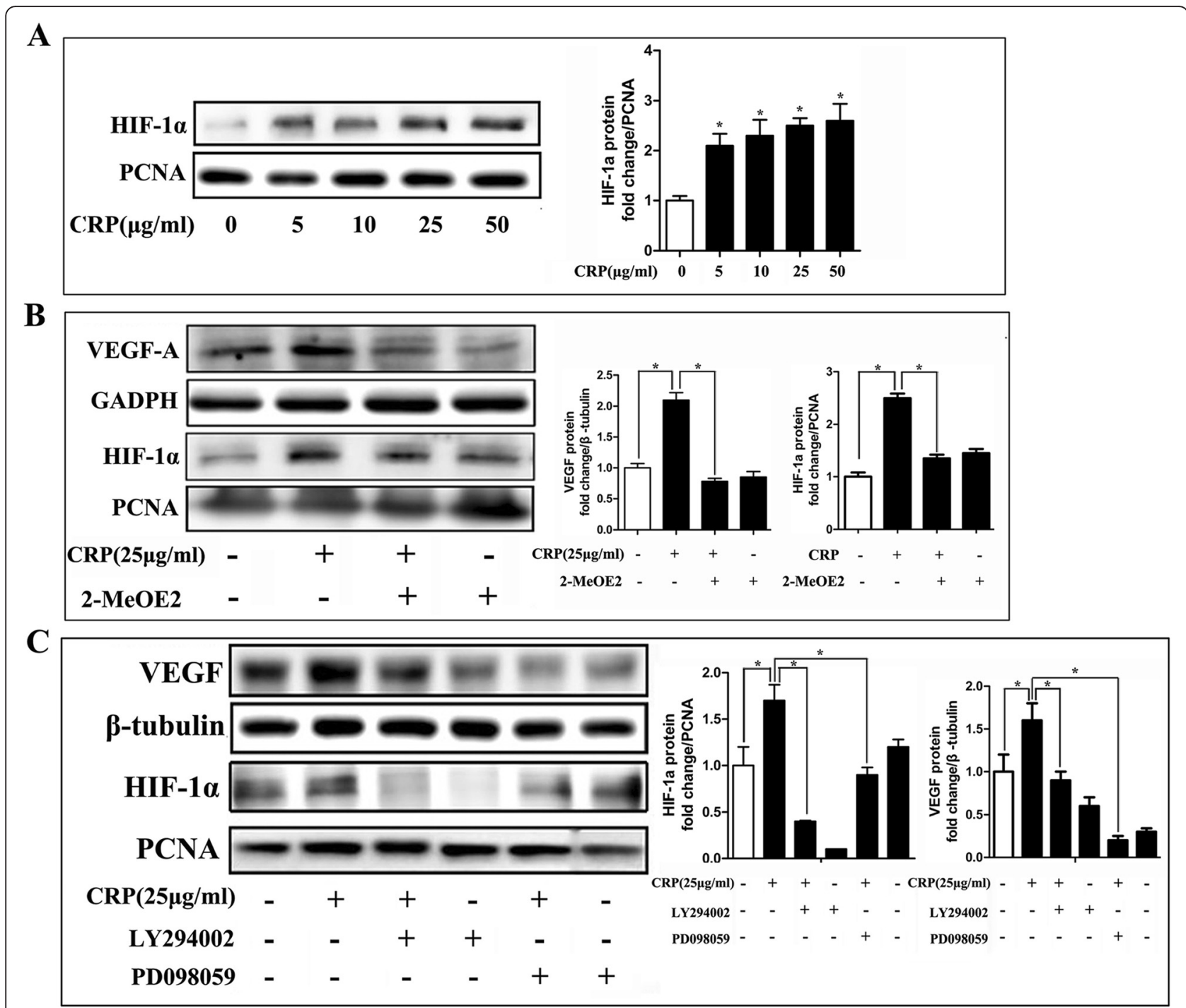

Fig. 6 CRP stimulated VEGF expression through HIF-1a, which was linked to activation of the PI3K/AKT1 and MAPK/ERK1/2 pathways. a CRP increased HIF-1a production as assessed by western blotting. b HIF-1a inhibitor (2-methoxyestradiol, $10 \mu \mathrm{M}$ ) prevented CRP-induced HIF-1a and VEGF protein expression. $\mathbf{c}$ Effects of kinase inhibitors on CRP-induced HIF-1a and VEGF expression examined by western blotting. MAPK and PI3K signaling pathway inhibition suppressed CRP-induced HIF-1a and VEGF expression. Columns, mean; bars, SE. ${ }^{*} p<0.05$. Results are representative of three independent experiments. CRP C-reactive protein, VEGF, vascular endothelial growth factor, HIF-1a hypoxia inducible factor-1a, PCNA, proliferating cell nuclear antigen

angiogenic factors, VEGF plays a key role in angiogenesis. VEGF secretion levels in ADSCs are low in cultured conditions, our results indicating that CRP can upregulate VEGF expression and production in ADSCs, which significantly increased endothelial cell tube formation in Matrigel, and that CRP pretreated ADSCs formed more functional vessels in vivo. As we know, MMPs play an important role in the formation and maintenance of new capillaries in vivo and in vitro. Previous studies showed that MMP-2 and MMP-9 were involved in coronary artery wall formation in experimental hypercholesterolemia, which coincides with vasa vasorum neovascularization [26]. We found that the addition of CRP significantly increased MMP-2 activity in a dose-dependent manner. In addition, we found CRP had no significant influence on the expression of inflammatory cytokines in ADSCs determined by RT-PCR, such as IL-10, IL- 6 and IL-1 $\beta$ (Additional file 1: Figure S3), indicating that CRP-induced angiogenesis in ADSCs may not be driven by inflammatory response. All of this evidence indicates that CRP can increase VEGF production and MMP-2 activity in ADSCs, which triggers endothelial cell activation and accelerates ECM degradation to play a substantial role in subsequent vasa vasorum proliferation.

To further explore the mechanisms of CRP-induced VEGF expression levels, we also examined the activation of HIF- $1 \alpha$, an important transcription factor that regulates VEGF expression via the binding of hypoxia-response 


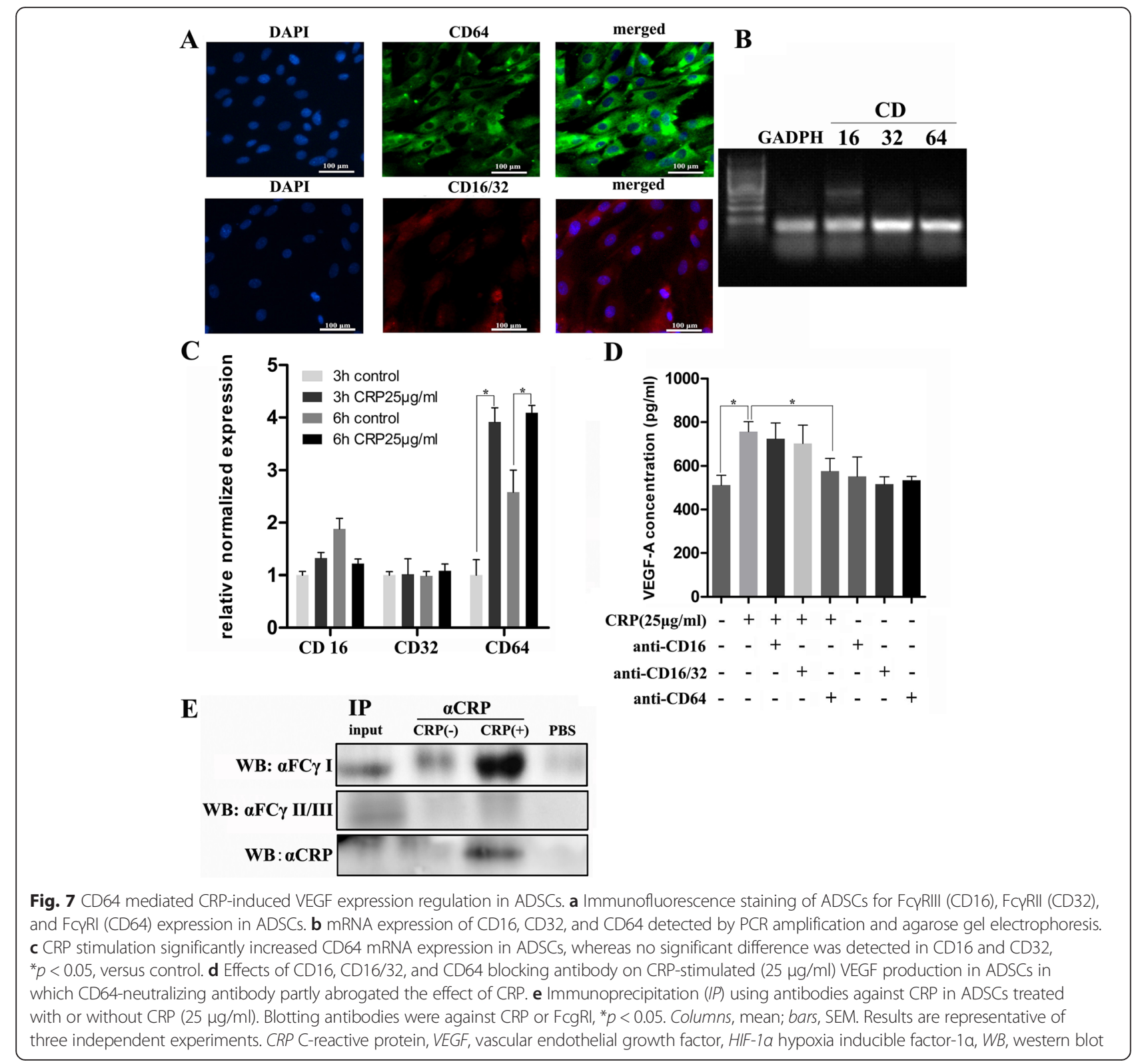

element (HRE) sites in the VEGF promoters in stem cells $[27,28]$ after ADSC CRP treatment. In normoxic conditions, HIF-1 is upregulated by growth factors, cytokines, hormones, and deregulated oncogenes. Our results indicated that CRP can increase HIF- $1 \alpha$ protein expression in the nucleus of ADSCs. Moreover, CRP-mediated VEGF and HIF-1 $\alpha$ expression changes can be abrogated by HIF$1 \alpha$ inhibitor (2-methoxyestradiol), which can depolymerize the microtubules and inhibit HIF- $1 \alpha$ nuclear accumulation and transcriptional activity, indicating that CRP promoted ADSC VEGF production via activating HIF- $1 \alpha$.

Since HIF prolyl hydroxylases (PHDs) regulate HIF-1 during hypoxia conditions, the PI3K/Akt and MAPK/ ERK pathways mediate primarily nonhypoxic HIF-1 and VEGF regulation [29]. Firstly, our results showed that
CRP can induce the PI3KAkt, MAPK/ERK1/2, and NF$\mathrm{kB} / \mathrm{IkB} \alpha$ signaling pathways. As we know, $\mathrm{IkB} \alpha$ phosphorylation can activate NF-kB (another VEGF transcription factor) to release it from $\mathrm{IkB} \alpha$ complex and bind to HRE sites in VEGF promoters in the nucleus. In the present study, however, only inhibiting the MAPK/ERK and PI3K/Akt pathways, but not the NF-kB pathway, could abrogate CRP-induced VEGF production, which is consistent with the other previous studies [30-32]. Our results further showed that ERK and Akt inhibition can suppress CRP-stimulated HIF- $1 \alpha$ and VEGF protein expression, which means that CRP stimulated VEGF expression through HIF-1 $\alpha$ in ADSCs was linked to the activation of canonic pathways (PI3K/AKT1 and MAPK/ ERK1/2) (see Fig. 8). 


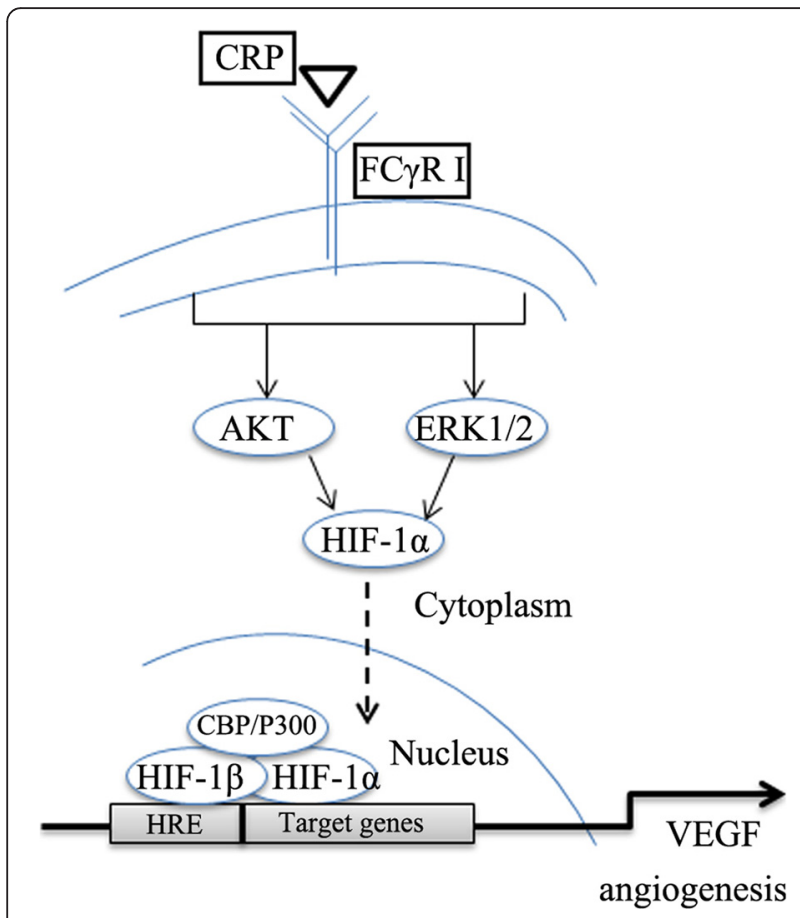

Fig. 8 Schematic representation of the molecular mechanism for CRP regulation of VEGF in ADSCs. CRP binds to the membrane surface antigen FCYRI (CD64) on ADSCs and then induces ERK1/2 and Akt phosphorylation, which activates HIF-1a to enter the nucleus and bind to hypoxia-response element sites in the VEGF promoter, stimulating VEGF gene and protein expression. CRP C-reactive protein, VEGF vascular endothelial growth factor, HIF-1a, hypoxia inducible factor-1a, HRE hypoxia-response element

CRP can bind to Fcr receptors (FcgRs), which lead to indirect (via classical complement) and direct opsonization (via FcrRs). We found that ADSCs expressed FcgRs, which are also expressed by many kinds of cell types; for example, immune, endothelial, smooth muscle, and tubular epithelial cells [20,33]. Blocking FcgRI can partially abrogate CRP-stimulated VEGF production, and CRP can bind and precipitate CD64 on ADSCs. Compared with CD16/ 32, CD64 displays higher affinity to CRP and modulates its actions within immune response cells [34]. This evidence suggested that FcgRI might serve as the major CRP receptor in ADSCs and as a novel therapeutic target for preventing CRP-induced ADSC angiogenesis in the inflammatory condition.

\section{Conclusion}

Our results showed that CRP had no significant effects on ADSC apoptosis and proliferation, whereas it increased ADSC migration via the PI3K/Akt signaling pathway. CRP also significantly stimulated VEGF production, mainly by activating HIF- $1 \alpha$ via the CD64/PI3K/Akt and MAPK/ ERK signal transduction pathways, and increased MMP-2 activity in ADSCs. Our findings will provide new evidence that CRP could promote growth of the vasa vasorum in atherosclerosis.

\section{Highlights}

1. Previous studies about CRP-induced atherosclerosis mostly focused on the intima and medium, such as the effect of CRP on endothelial cells, SMC, mononuclear cells, and so forth. For the first time, we hypothesized that CRP may play an important role in the development of atherosclerosis by promoting mesenchymal stem cell angiogenesis in periadventitial adipose tissue, and we found that CRP can promote ADSC-induced angiogenesis by stimulating VEGF expression and increasing the activity of MMP-2 in vitro, providing new evidence for CRP as a cardiovascular risk factor.

2. For the first time, we found that CRP binds activating CD64 on ADSCs, rather than CD16/32. CD64 may act as a novel therapeutic target for preventing CRP-induced ADSC angiogenesis in the inflammatory condition.

\section{Additional file}

Additional file 1: Table S1. The identification of mADSCs and the effect of CRP on the differentiation potential and inflammation marker in ADSCs. (DOCX $737 \mathrm{~kb})$

\section{Abbreviations}

ADSC, adipose-derived stem cell; CM, condition medium; CRP, C-reactive protein; EGM, endothelial growth medium; ELISA, enzyme-linked immunosorbent assay; FGF, fibroblast growth factor; HGF, hepatocyte growth factor; HIF-1a, hypoxia inducible factor-1a; HRE, hypoxia-response element; HUVEC, human umbilical vein endothelial cell; MMP, matrix metalloproteinase; PVAT, perivascular adipose tissue; qRT-PCR, quantitative real-time PCR; VEGF, vascular endothelial growth factor

\section{Funding}

This work was supported by the National Natural Science Foundation of China (81270212,91439125,81570329), and Guangdong Natural Science Fund Committee, China (2015A030312009,2016A030313263).

\section{Availability of supporting data}

The primer sequences are presented in Additional file 1: Table S1.

The characterization of mADSCs is shown in Additional file 1: Figure S1. The effects of CRP on adipogenic and osteogenic differentiation of ADSCs is shown in Additional file 1: Figure S2.

The effect of CRP on the expression of inflammatory markers in ADSCs is shown in Additional file 1: Figure S3.

\section{Authors' contributions}

JYC performed most cell experiments, collection of data, data analysis, and manuscript writing. ZJG carried out collection of data, data analysis and interpretation, and manuscript writing. MXW participated in cell preparation and cultivation, and immunohistochemistry, and helped to draft the manuscript. YY, JHZ and ZYZ carried out data analysis and interpretation, and revised the manuscript critically for important content. JSO, YXC and JFW participated in the conception and design, financial support, and data analysis and interpretation. All authors read and approved the manuscript. 


\section{Competing interests}

The authors declare that they have no competing interests.

\section{Consent for publication}

The authors have approved the content and agree to submit it for publication.

\section{Ethical approval and consent to participate}

The animal experiments were conducted according to the guidelines and ethical standards of the Animal Care and Use Ethics Committees of Sun Yat-Sen University (IACUC-DB-16-070).

\section{Author details}

'Department of Cardiology, Sun Yat-sen Memorial Hospital, Sun Yat-sen University, Guangzhou 510120, People's Republic of China. 'Guangdong Province Key Laboratory of Arrhythmia and Electrophysiology, Guangzhou 510120, People's Republic of China. ' ${ }^{3}$ Laboratory of RNA and Major Disease of Brain and Heart, Sun Yat-sen Memorial Hospital, Sun Yat-sen University, Guangzhou 510120, People's Republic of China. Division of Cardiac Surgery, The First Affiliated Hospital, Sun Yat-sen University, Guangzhou 510080, People's Republic of China. ${ }^{5}$ Guangdong Province Engineering Laboratory for Diagnosis and Treatment of Vascular Diseases, Guangzhou 510080, People's Republic of China. 'Department of Anesthesiology, University of Virginia, Health Science Center, Charlottesville, VA, USA

\section{Received: 18 May 2016 Revised: 4 July 2016 Accepted: 26 July 2016} Published online: 16 August 2016

\section{References}

1. Pepys MB, Hirschfield GM. C-reactive protein: a critical update. J Clin Invest. 2003:111:1805-12.

2. Ridker PM. A test in context: high-sensitivity C-reactive protein. J Am Coll Cardiol. 2016:67:712-23.

3. Emerging Risk Factors Collaboration, Kaptoge S, Di Angelantonio E, Lowe G, Pepys MB, Thompson SG, et al. C-reactive protein concentration and risk of coronary heart disease, stroke, and mortality: an individual participant meta-analysis. Lancet. 2010;375:132-40.

4. Liu C, Wang S, Deb A, Nath KA, Katusic ZS, McConnell J, et al. Proapoptotic, antimigratory, antiproliferative, and antiangiogenic effects of commercial C-reactive protein on various human endothelial cell types in vitro: implications of contaminating presence of sodium azide in commercial preparation. Circ Res. 2005:97:135-43.

5. Taylor KE, Giddings JC, van den Berg CW. C-reactive protein-induced in vitro endothelial cell activation is an artefact caused by azide and lipopolysaccharide. Arterioscler Thromb Vasc Biol. 2005;25:1225-30.

6. Lane T, Wassef N, Poole S, Mistry Y, Lachmann HJ, Gillmore JD, et al. Infusion of pharmaceutical-grade natural human C-reactive protein is not proinflammatory in healthy adult human volunteers. Circ Res. 2014;114:672-6.

7. Moyle B, Caplice N, Purushothaman KR. Plaque neovascularization and antiangiogenic therapy for atherosclerosis. J Am Coll Cardiol. 2007:49:2073-80.

8. Mulligan-Kehoe MJ. The vasa vasorum in diseased and nondiseased arteries. Am J Physiol Heart Circ Physiol. 2010;298(2):H295-305.

9. Manka D, Chatterjee TK, Stoll LL, Basford JE, Konaniah ES, et al. Transplanted perivascular adipose tissue accelerates injury-induced neointimal hyperplasia: role of monocyte chemoattractant protein-1. Arterioscler Thromb Vasc Biol. 2014;34:1723-30.

10. Brown NK, Zhou Z, Zhang J, Zeng R, Wu J, Eitzman DT, et al. Perivascular adipose tissue in vascular function and disease: a review of current research and animal models. Arterioscler Thromb Vasc Biol. 2014:34:1621-30.

11. Klein D, Weisshardt $P$, Kleff $V$, Jastrow $H$, Jakob HG, Ergün S. Vascular wall-resident CD44+ multipotent stem cells give rise to pericytes and smooth muscle cells and contribute to new vessel maturation. PLoS One. 2011;6(5):e20540.

12. Hribal ML, Fiorentino TV, Sesti G. Role of $\mathrm{C}$ reactive protein (CRP) in leptin resistance. Curr Pharm Des. 2014;20:609-15.

13. Chen Y, Wang X, Mai J, Zhao X, Liang Y, Gu M, et al. C-reactive protein promotes vascular endothelial dysfunction partly via activating adipose tissue inflammation in hyperlipidemic rabbits. Int J Cardiol. 2013;168:2397-403.
14. Slevin M, Matou-Nasri S, Turu M, Luque A, Rovira N, Badimon L. Modified C-reactive protein is expressed by stroke neovessels and is a potent activator of angiogenesis in vitro. Brain Pathol. 2010;20(1):151-65.

15. Boras E, Slevin M, Alexander MY, Aljohi A, Gilmore W, Ashworth J, et al. Monomeric C-reactive protein and Notch-3 co-operatively increase angiogenesis through PI3K signalling pathway. Cytokine. 2014;69(2):165-79.

16. Turu MM, Slevin M, Matou S, West D, Rodriguez C, Luque A. C-reactive protein exerts angiogenic effects on vascular endothelial cells and modulates associated signalling pathways and gene expression. BMC Cell Biol. 2008;9:47.

17. Bello G, Cailotto F, Hanriot D, Kolopp-Sarda MN, Latger-Cannard V, Hess K, et al. C-reactive protein (CRP) increases VEGF-A expression in monocytic cells via a Pl3-kinase and ERK1/2 signaling dependent pathway. Atherosclerosis. 2008;200(2):286-93.

18. Zuk PA, Zhu M, Mizuno H, Huang J, Futrell JW, Katz AJ, et al. Multilineage cells from human adipose tissue: implications for cell-based therapies. Tissue Eng. 2001;7(2):211-28.

19. Ha JM, Kim MR, Oh HK, Lee BH, Ahn HY, Shin JC, et al. Out growing endothelial progenitor-derived cells display high sensitivity to angiogenesis modulators and delayed senescence. FEBS Lett. 2007;581:2663-9.

20. Liu F, Chen HY, Huang XR, Chung AC, Zhou L, Fu P, et al. C-reactive protein promotes diabetic kidney disease in a mouse model of type 1 diabetes. Diabetologia. 2011;54:2713-23

21. Yang J, Wezeman $M$, Zhang $X$, Lin $P$, Wang $M$, Oian J, et al. Human C-reactive protein binds activating Fcgamma receptors and protects myeloma tumor cells from apoptosis. Cancer Cell. 2007:12:252-65.

22. Botero TM, Son JS, Vodopyanov D, Hasegawa M, Shelburne CE, Nör JE. MAPK signaling is required for LPS-induced VEGF in pulp stem cells. Dent Res. 2010;89:264-9.

23. Ries C, Egea V, Karow M, Kolb H, Jochum M, Neth P. MMP-2, MT1-MMP, and TIMP-2 are essential for the invasive capacity of human Mesenchymal Stem cells: differential regulation by inflammatory cytokines. Blood. 2007:109(9):4055-63.

24. Koellensperger E, Gramley F, Preisner F, Leimer U, Germann G, Dexheimer V, et al. Alterations of gene expression and protein synthesis in co-cultured adipose tissue-derived stem cells and squamous cell-carcinoma cells: consequences for clinical applications. Stem Cell Res Ther. 2014;5(3):65.

25. Kinnaird T, Stabile E, Burnett MS, Lee CW, Barr S, Fuchs S, et al. Marrow-derived stromal cells express genes encoding a broad spectrum of arteriogenic cytokines and promote in vitro and in vivo arteriogenesis through paracrine mechanisms. Circ Res. 2004;94(5):678-85.

26. Wilson SH, Herrmann J, Lerman LO, Holmes Jr DR, Napoli C, Ritman EL, et al Simvastatin preserves the structure of coronary adventitial vasa vasorum in experimental hypercholesterolemia independent of lipid lowering. Circulation. 2002;105:415-8

27. Li TS, Hamano K, Suzuki K, Ito H, Zempo N, Matsuzaki M. Improved angiogenic potency by implantation of ex vivo hypoxia prestimulated bone marrow cells in rats. Am J Physiol Heart Circ Physiol. 2002;283:H468-73.

28. Carmeliet $P$, Jain RK. Angiogenesis in cancer and other diseases. Nature. 2000:407:249-57.

29. Agani $\mathrm{F}$, Jiang BH. Oxygen-independent regulation of HIF-1: nove involvement of PI3KNAKT/mTOR pathway in cancer. Curr Cancer Drug Targets. 2013;13(3):245-51.

30. Hou Y, Ryu CH, Jun JA, Kim SM, Jeong CH, Jeun SS. IL-8 enhances the angiogenic potential of human bone marrow mesenchymal stem cells by increasing vascular endothelial growth factor. Cell Biol Int. 2014;38:1050-9.

31. Herrmann JL, Weil BR, Abarbanell AM, Wang Y, Poynter JA, Manukyan MC. IL-6 and TGF-alpha costimulatemesenchymal stem cell vascular endothelial growth factor production by ERK-, JNK-, and PI3K-mediated mechanisms. Shock. 2011;35:512-6.

32. Hye Kim J, Gyu Park S, Kim WK, Song SU, Sung JH. Functional regulation of adipose-derived stem cells by PDGF-D. Stem Cells. 2015;33:542-56.

33. Mineo C, Gormley AK, Yuhanna IS, Osborne-Lawrence S, Gibson LL, Hahner L, et al. Fcgamma RIIB mediates C-reactive protein inhibition of endothelial NO synthase. Circ Res. 2005;97:1124-31.

34. Stein MP, Edberg JC, Kimberly RP, Mangan EK, Bharadwaj D, et al. C-reactive protein binding to FcgammaRlla on human monocytes and neutrophils is allele-specific. J Clin Invest. 2000;105:369-376. 